\title{
Risco: a percepção da comunidade ribeirinha do Rio dos Sinos em relação ao uso de defensivos agrícolas
}

\author{
Risk: the perceptions of the riverside comunity of Sinos River in relation to the use of agrochemicals \\ Camila Rambow ', Valesca Beatriz Streppel Panichi², João Alcione Sganderla Figueiredo ${ }^{3}$ \\ 'Universidade Federal de Ciências da Saúde de Porto Alegre, Porto Alegre, Brasil \\ ${ }^{2,3}$ Universidade Feevale, Novo Hamburgo, Brasil
}

\begin{abstract}
Resumo
As alterações geradas pelo desenvolvimento industrial e o aumento populacional, motivou uma adaptação da produção de alimentos. O uso de agrotóxicos em lavouras aumenta a produção e a rentabilidade. Se por um lado auxilia à produção, por outro representa riscos de poluição. Em decorrência deste cenário propomos uma reflexão frente à percepção de risco da comunidade ribeirinha do Vale do Rio dos Sinos em relação ao uso de defensivos agrícolas e a sua saúde. Aplicaram-se 89 questionários abordando questões sobre a utilização de agrotóxicos, a saúde dos manipuladores e também frente a prejuízos ao meio ambiente. Os resultados deste levantamento apontam que 38,2\% dos entrevistados concordam completamente que é possível a produção agrícola sem o uso de agrotóxicos e inseticidas, $73,9 \%$ concordam completamente que os produtos químicos utilizados causam danos à saúde, para $82 \%$ não existe a necessidade de uso de produtos químicos no seu trabalho. Entretanto $86,5 \%$ acreditam que estes não oferecem risco ao meio ambiente e $7,9 \%$ relataram apresentar problemas de saúde relacionada ao uso de agrotóxicos na lavoura. A análise deste estudo se dá por meio das teorias da sociedade de risco proposta por Douglas, Giddens, Beck e as relações de representação, proposta por Goffman.
\end{abstract}

Palavras-chave: Percepção de risco, comunidade ribeirinha, Vale do Rio dos Sinos, agrotóxicos, defensivos agrícolas.

\begin{abstract}
The changes generated by industrial development and population growth, led to an adaptation of food production. The use of pesticides in crops increases production and profitability. In one hand it helps the production, but there are risks of pollution. As a result of this scenario we propose a reflection across the risk perception of the riverside community of Vale do Rio dos Sinos regarding the use of pesticides and health. Overall, 89 questionnaires addressing issues on the use of pesticides, the health of handlers and also against environmental damage were applied. The results of this survey indicate that $38.2 \%$ of respondents agree completely that agricultural production is possible without the use of pesticides and insecticides, $73.9 \%$ completely agree that the chemicals cause damage to health, there is a $82 \%$ need to use chemicals in their work. However $86.5 \%$ believe that they do not offer risk to the environment and $7.9 \%$ reported having health problems related to the use of pesticides in farming. The analysis of this study is through theories of risk society proposed by Douglas, Giddens, Beck and relations of representation proposed by Goffman.
\end{abstract}

Keywords:Risk perception, riverside community, Vale do Rio dos Sinos, agrochemical, pesticides. 


\section{INTRODUÇÃO}

O presente trabalho apresenta uma reflexão acerca dos riscos do uso de agrotóxicos e a percepção da comunidade ribeirinha envolvida com essas substâncias. O processo de desenvolvimento industrial gera mudanças nas relações de trabalho, na produção, na obtenção e na utilização de produtos. Essas mudanças ocasionam problemas como o descarte de resíduos industriais e domésticos não tratados, além da contaminação ocasionada pelo uso de agrotóxicos nas lavouras. A utilização de agrotóxicos é benéfica para o setor rural, ao gerar maior rendimento e aumento de produção. Em contrapartida, ocasiona riscos ambientais e a saúde dos consumidores e manipuladores. Percebe-se, em princípio, uma questão ambiental esquecida em detrimento do privilégio de mercado. Visto isso, o estudo tem como objetivo analisar a percepção de risco da comunidade ribeirinha do Vale do Rio dos Sinos em relação ao uso de agrotóxicos nas lavouras e as consequências destes a saúde. Esse estudo é de grande relevância, já que o discurso sobre a preocupação com o meio ambiente assume um papel de maior destaque, em uma realidade em que as ações, cada vez mais, assumem caráter comercial. Frente a esse cenário torna-se importante um estudo sobre a percepção de risco, visto que a utilização de agrotóxicos e sua disseminação e abrangência estão em um crescente nos últimos anos, expondo muitas pessoas a vários riscos, tornando-se assim uma sociedade de risco global proposta nas teorias de Ülrich Beck.

A população do estudo vive nas margens do Rio dos Sinos. Esse é o principal rio da Bacia Hidrográfica Rio dos Sinos situada na América do Sul -Brasil- a noroeste do Estado do Rio Grande do Sul é constituída por 32 municípios, ocupando uma área de $3.820 \mathrm{~km}^{2}$ o que representa $1,5 \%$ da área total do Estado. O Rio dos Sinos possui $190 \mathrm{~km}$ de longitude, cuja nascente localiza-se no Município de Caraá e desemboca no Rio Jacuí. Para melhor caracterizá-lo, o Rio dos Sinos foi dividido em três sub-trechos: trecho superior, trecho médio e o trecho inferior. Na porção superior (de Caará até Rolante) as áreas são de baixa densidade populacional, com pequenas propriedades rurais, cuja agricultura varia entre culturas de arroz, cana de açúcar, hortaliças, entre outras. Nessa região, a pecuária é pouco desenvolvida, mas encontram-se pequenas criações de gado leiteiro, de suínos e aves. Já a porção média (entre Taquara e Sapiranga), apresenta grande concentração populacional e industrial, em que os centros urbanos, como Campo Bom, Novo Hamburgo, São Leopoldo, Estância Velha, Portão, Sapucaia do Sul, Esteio e Canoas.

O Rio dos Sinos recebe grande quantidade de descartes de resíduos industriais e domésticos não tratados, existe uma exploração e uso ilegal das águas para irrigar as culturas de arroz e, ainda, recebe a contaminação dos resíduos de agrotóxicos que prejudicam a qualidade da água. Salienta-se aqui, sua importância para o abastecimento de água da região e para a sobrevivência de espécies que nela habitam. Um dos exemplos dos prejuízos ambientais causados pela poluição foi a mortandade dos peixes ocorrida em outubro de 2006 ocasionada pelo rejeite inadequado das indústrias, originando a morte de mais de 100 toneladas de peixes. A contaminação da água é um cenário de risco onde todos que dependem dela, principalmente a comunidade ribeirinha do Rio dos Sinos, que são "obrigados" a conviver com este risco. Neste sentido, estudar a percepção e comportamento relacionado aos riscos é de fundamental importância para qualquer projeto de implantação de políticas públicas, entre outros.

\section{METODOLOGIA}

Para estudar a percepção do risco aplicou-se 89 questionários em sujeitos residentes na comunidade ribeirinha do Vale do Rio dos Sinos, nos 13 municípios canalizados pelo rio (Caraá, Santo Antônio da Patrulha, Taquara, Parobé, Sapiranga, Novo Hamburgo, Campo Bom, São Leopoldo, Portão, Sapucaia do Sul, Nova Santa Rita, Esteio e Canoas). O questionário aplicado apresenta questões fechadas de múltipla escolha. Além de obter dados sociodemográficos, as questões abordavam os seguintes temas: agrotóxicos, saúde, meio ambiente, responsabilidade, percepção de risco, água.

As questões respondidas pelos ribeirinhos do Rio dos Sinos são analisadas por meio das teorias da sociedade de risco, como a ideia de aceitabilidade do risco proposta por Mary Douglas, a passividade e conformidade por Anthony Giddens, a irresponsabilidade organizada Ülrich Beck e a interação social, como um processo fundamental de identificação e diferenciação dos indivíduos e grupos proposta por Erving Goffman. 


\section{RESULTADOS E DISCUSSÃO}

\section{I PROCESSO HISTÓRICO RURAL E URBANIZAÇÃO/INDUSTRILIZAÇÃO}

Mediante ao aumento da produção e a todas as formas de comercialização relacionadas com o couro tornou a região do Vale do Rio dos Sinos um pólo coureiro calçadista reconhecido no mundo todo pela tradição desse setor, passando de uma atividade artesanal à industrial.

A Bacia do Rio dos Sinos abrange 13 municípios, possuindo 1,5\% da área total do Estado do Rio Grande do Sul, com uma população aproximada de 975.000 habitantes, sendo que 90,6\% ocupam as áreas urbanas e 9,4\% estão nas áreas rurais. As áreas urbanas predominam, mas a porção superior do Rio dos Sinos é mais rural, apresentando pequenas propriedades rurais, pecuária e agricultura, principalmente da cultura do arroz. O plantio de arroz necessita de uma demanda muito alta de água e normalmente estas culturas de arroz localizam-se próximos a margens dos rios, para facilitar a retirada de água.

Assim como, na produção de arroz, faz-se necessário a utilização de agrotóxicos a fim de exterminar as pragas, buscando uma maior produtividade e rentabilidade. Atualmente predominam no Estado do Rio Grande do Sul estabelecimentos de agricultura familiar, conforme os dados do IBGE do censo agropecuário de 2006, em que dos 441.467 totais de estabelecimentos, 378.546 são utilizados pela agricultura familiar (Lei 11.326) e 62.921 é caracterizado como não familiar.

O uso maior de agrotóxicos fica concentrado em maiores plantações, onde o objetivo é uma grande produção, buscando uma maior rentabilidade com menores perdas. A agricultura familiar pode vir a fazer uso de agrotóxicos, mas a plantação é em menor escala e consequentemente menor quantidade.

Na região de estudo além da problemática da utilização de agrotóxicos, a cultura de arroz contribuiu também para a falta de água da região. Visto isso, os 43 produtores de arroz (que produzem em 2.400 hectares e colhem 20 mil toneladas por ano) que possuem a autorização de órgãos ambientais para instalar bombas para retirar a água do Rio dos Sinos, afirmam que não o prejudicam. Porém, os Prefeitos alegam que $60 \%$ da água retirada são destinadas as lavouras, contudo os agricultores dizem que não usam nem a metade. A fim de solucionar essa realidade de falta de água, a Associação dos Prefeitos do Vale do Rio dos Sinos aprovou o encaminhamento do Consórcio Pró-Sinos pelo fim da produção de arroz na bacia do Rio dos Sinos. A proposta é que até 2015 o cultivo do arroz seja extinto. Conforme o diretor executivo do Pró-Sinos, Júlio Dorneles, a ideia é que a cada ano a área de plantio seja reduzida em $25 \%$, iniciando em 2012

\subsection{UsO DE AGROTÓXICOS E SEUS IMPACTOS}

A utilização de agrotóxicos teve origem no Brasil nas décadas de 1960 e 1970 onde a automação na lavoura progredia com a implantação de máquinas e o uso de agrotóxicos destinados para o aumento de produção. Essa situação foi estimulada pelo Sistema Nacional de Crédito Rural que concedia um empréstimo e a fixação do valor a ser gasto com o agrotóxico. Portanto, o seu uso era símbolo de modernidade no campo (PERES, 1999).

Com o aumento da população e a crescente urbanização, a produção de alimentos teve de adequar-se com a diminuição de terras produtivas para plantação, tornando-se, ainda mais preciso a utilização de agrotóxicos (GRISOLIA, 2005). Entretanto, seu uso no meio ambiente é na maioria das vezes nocivo. Os defensivos são destinados a diferentes situações, rurais ou urbanas, podendo ser:

a) Controle de pragas em jardins; b) controle de insetos, especialmente cupins, nas residências; c) controle de outras pragas em residências; d) controle das populações de ratos nas cidades; e) controle de fungos em ambientes fechados e em diferentes utensílios, como caixas de papelão, madeiras, móveis, tecidos, etc; f) controle de formigas; g) erradicação da vegetação ao longo das rodovias e ferrovias; h) controle de vetores de doenças humanas e i) na pecuária, e outros (GRISOLIA, 2005, p. 24).

De forma geral os agrotóxicos são empregados para combater pragas, ou seja, são feitos para exterminar, combater ou dificultar a vida; desta forma quando atingem a um organismo não-alvo (microorganismos, minhocas, peixes, algas, abelhas, aves, e mamíferos) prejudicam a sua vida. Os usos desses produtos contaminam a água, a atmosfera, a terra e o solo, permanecendo no meio ambiente, entrando na cadeia alimentar e ciclos biogeoquímicos, provocando efeitos tóxicos independente do ser vivo.

Para uma aplicação adequada do produto e com segurança para o manipulador, se faz necessário 
o uso de uma roupa especial (luvas, sapatos, etc.), ou seja, Equipamento de Proteção Individual (EPI). Caso a pessoa não utilize tais equipamentos estará mais exposta ao risco de contaminação.

A fim de classificar os efeitos nocivos à saúde devido ao uso de agrotóxicos, as empresas devem informar ao Instituto Brasileiro do Meio Ambiente e dos Recursos Naturais Renováveis (Ibama) as propriedades físico-químicas das substâncias do produto, os resultados de testes, bem como os estudos referente a mobilidade e persistência em solo, fotólise, hidrólise, testes de toxicidade aguda e crônica realizado em organismos não-alvos, estudos de bioconcentração em peixes, e de potencial mutagênico, teratogênico e carcinogênico (PERES, 2003).

Conforme esses parâmetros, os agrotóxicos são classificados: classe I produtos impeditivos de obtenção de registro, altamente perigoso ao meio ambiente; classe II produtos muitos perigosos ao meio ambiente; classe III produtos perigosos ao meio ambiente e classe IV produtos pouco perigosos ao meio ambiente (PERES, 2003, p. 28).

Os efeitos dos agrotóxicos sobre a saúde podem ser classificados em dois tipos: agudos e crônicos. Efeito agudo é aquele decorrente da exposição à concentração de um ou mais tóxicos que causam dano no período de 24 horas; já o efeito crônico é resultante de exposição contínua de doses mais baixas aparecendo os danos em um período depois da exposição, respectivamente. De acordo com a origem do produto (funcional e química), assim como da intoxicação (aguda e crônica) o indivíduo pode manifestar sintomas distintos, o que comprova os prejuízos que podem acarretar a sua saúde.

\subsection{PercepÇÃo de RISCO}

Vivemos atualmente em uma sociedade de risco, onde convivemos com riscos globais, oriundos do desenvolvimento industrial e agrícola, que atingem vários segmentos da população mundial. Essa é a sociedade que se auto-confronta com os resultados negativos de seu progresso, como proposto da "Teoria de Modernização Reflexiva" (Beck, 2000). Se por um lado, a percepção de risco torna-se fundamental, por outro, na descrição de alguns autores, ela é subjetiva, variando conforme a interpretação do indivíduo, baseado nas as suas experiências e valores. Para Douglas (1996) o que para uma pessoa é considerado risco, para a outra pode não ser.

De acordo com Beck, os riscos não só surgem como "acidentes" ou "efeitos colaterais", ocasionados devido a consequências negativas da tecnologia, mas também estão mascarados nos níveis de aceitabilidade de contaminação. O risco não é contabilizado na sua extensão. O consumo de alimentos expostos a agrotóxicos geram individualmente, um nível aceitável desses resíduos. Entretanto, o consumo diário de vários alimentos expostos gera uma sobreposição de resíduos nos alimentos ingeridos. Esta sobreposição não é questionada e não se discute seu nível de prejuízos ao longo da vida. Trata-se de um quadro grave, pois o uso de agrotóxicos é uma fonte de risco globalizada, em decorrência de sua ampla disseminação.

Antigamente, segundo Beck, os riscos eram vistos como pessoais, mas atualmente eles são globais, atravessando as fronteiras nacionais e de classes. As pessoas, frente à exposição de poluentes, passam a serem mais conscientes reflexivamente a esta contaminação. Contudo, para o autor ainda existem pessoas mais afetadas pelos riscos do que outras, ou seja, a distribuição dos riscos seguem as desigualdades sociais (Beck, 1992). Frente ao uso de agrotóxicos e seus resíduos nos alimentos, percebe-se, no entanto, uma distribuição maior de riscos, em decorrência da extensão de pessoas que consomem estes alimentos.

Uma alternativa como proteção ao risco de contaminação por produtos químicos é a aquisição de alimentos orgânicos. Todavia, a agricultura orgânica não produz todos os alimentos. Entretanto, trata-se de alimentos produzidos de forma diferenciada que geram um custo maior para o consumidor adquirir. Quando Beck (1992) analisa que a distribuição dos riscos seguem desigualdades sociais, fica claro frente à opção de alimentos orgânicos. Uma grande parte da população não conseguiria consumir este tipo de alimento em decorrência do seu preço elevado.

Outra situação de exposição ao risco é frente à aplicação dos agrotóxicos nas lavouras. Ao manipular o agrotóxico, o trabalhador está mais exposto ao risco de contaminação. Situação agravada se não estiver utilizando o EPI de forma correta. Os agrotóxicos permanecem no meio ambiente atingindo diferentes organismos não alvos. A contaminação pode estar presente na água ou no solo, interferindo na produção do alimento. O uso de agrotóxicos nas lavouras para o plantio de alimentos é atualmente sinônimo de produção, gerando produtos com maior rentabilidade (visualmente mais bonitos para o consumo e sem maiores perdas no cultivo). Uma adequação à alta demanda do mercado 
para grandes produções de alimentos.

Em decorrência de um cenário de exposição aos riscos oriundos da contaminação por defensivos agrícolas, se fez necessário realizar um estudo analisando a percepção do risco para a comunidade ribeirinha do Vale do Rio dos Sinos em relação ao uso de agrotóxicos nas lavouras e as consequências à saúde. Para este levantamento, aplicou-se um questionário fechado, com perguntas a respeito da produção sem o uso de agrotóxicos ou inseticidas, a necessidade de sua utilização no trabalho, se o individuo apresentou problemas de saúde ao utilizá-los ou se oferece risco ao meio ambiente. Para a análise das questões e suas respostas, fundamentaram-se nas teorias do risco ambiental e percepção do risco, baseadas nas ideias da aceitabilidade do risco do meio ambiente proposta por Mary Douglas; passividade e conformidade por Anthony Giddens; irresponsabilidade organizada Ülrich Beck e a interação social um processo fundamental de identificação e diferenciação dos indivíduos e grupos proposta por Erving Goffman.

Quanto à possibilidade da produção agrícola sem o uso de agrotóxicos, 38,2\% dos entrevistados concordam completamente que é possível à produção agrícola sem o uso de agrotóxico e inseticida, e $15,7 \%$ concordam e $7,9 \%$ concordam parcialmente com esta afirmativa. Percebe-se que há um impulso no discurso dos entrevistados, para a produção do chamado alimento "orgânico", entretanto, isso não significa que não se utiliza algum tipo de inseticida, logo, pode haver discordância entre discurso e prática. Ademais, os entrevistados relataram praticar pequenas plantações (que a princípio não demanda um uso maior de agrotóxico) o que poderia ter contribuído para concordarem de que é possível a produção sem o uso de algum defensivo agrícola. Percebeu-se, nas entrelinhas, que as respostas eram dadas com um temor de serem julgados moralmente por tal prática, o que de certa forma poderia comprometer tais dados, mas que ficou somente na subjetividade dos entrevistadores frente a estas respostas. Uma percentagem menor dos entrevistados diverge, entendendo que $18 \%$ destes discordam, e 16,9\% discordam totalmente, afirmando que é necessária a utilização de agrotóxicos e inseticidas para a produção agrícola. Mesmo um contingente superior a $60 \%$ dos entrevistados afirmando ser possível uma produção sem uso de defensivos, podemos questionar que frente a tal prática, na realidade, economicamente possa ficar inviável para uma quantidade maior de produtores que buscam melhores rentabilidade e/ou produção e fazem o uso de agrotóxicos na sua prática laboral.

Quanto aos malefícios e danos causados pelo uso de produtos químicos a saúde do trabalhador, verificou-se que $73,9 \%$ dos entrevistados concordam completamente que os produtos químicos utilizados causam danos à saúde do trabalhador, e 15,9\% concordam e 5,7\% concordam parcialmente com esta afirmativa. Ficou explícito para os entrevistados que os produtos químicos prejudicam a saúde do trabalhador, pois identificam os males e doenças que eles causam, principalmente pela falta de EPI adequado ao manipulá-los, tornando mais fácil sua contaminação. Houve uma pequena parcela dos entrevistados que discordam $(2,3 \%)$ e que discordam totalmente $(1,1 \%)$ que o uso de agrotóxico acarreta danos à saúde do trabalhador. Importante relacionar que mesmo os entrevistados sabendo que o seu uso traz malefícios, não conseguem desarticular o seu uso da prática, provavelmente por obterem resultados quantitativos e qualitativos (maior produção, produtos de melhor aparência e ganhos econômicos) melhores. Questiona-se também a possibilidade de compreensão destes indivíduos, pois o não perceber o uso de agrotóxicos como risco, tratar-se de uma demanda da subjetividade individual que é definida pela compreensão de um risco, conforme Erving Goffman pontua. Em alguns relatos, os entrevistados dizem que seus familiares ou vizinhos usaram "venenos" nas plantas em boa parte de suas vidas, mas que morreram de outras doenças, e que suas mortes não foram em decorrência desta exposição. Evidenciam-se as experiências do cotidiano, o chamado "mundo da vida", proposto por Anthony Giddens.

Tratando-se do cotidiano laboral, $82 \%$ dos entrevistados dizem que não existe a necessidade de uso de produtos químicos no seu trabalho. Decorre-se este percentil do fato de muitos destes realizarem afazeres domésticos, estarem aposentados (oriundos da indústria) ou por já plantarem produtos sem o uso de agrotóxicos. Já para 16,9\%, existe a necessidade do uso de produtos químicos na sua atividade profissional. Dentre os participantes que responderam que fazem o uso de produtos químicos na sua atividade o percentual de $40 \%$ utiliza agrotóxicos na execução de seu labor, $40 \%$ é por exposição ocupacional, $13,3 \%$ é por outras respostas e houve para $6,7 \%$ das respostas como o uso de produto natural. Percebemos entre os entrevistados, que utilizam esses produtos é, realmente devido ao seu trabalho, sendo "obrigados" a utilizá-los, pois é a forma de sustentar-se, podendo ser analisado este fato na próxima questão. 
Frente ao risco ao meio ambiente em relação aos agrotóxicos utilizados no teu trabalho, para $86,5 \%$ dos entrevistados acreditam que estes não oferecem risco ao meio ambiente. Verifica-se uma correlação com a resposta anterior, pois conforme os entrevistados, estes não necessitavam utilizar produtos químicos no seu trabalho, logo esta prática não ofertava riscos ao meio ambiente. Existe para um percentual de $4,5 \%$ dos entrevistados que dissocia a utilização do produto (defensivo) na sua atividade profissional, frente aos prejuízos ao meio ambiente. O indivíduo até identifica o uso como risco, mas por algum motivo, podendo ser por seu trabalho ser a fonte de seu sustento, sujeita-se ao risco, vindo a aceita-lo, tomando uma atitude passiva frente a ele, conforme a ideia de passividade e conformidade de Anthony Giddens. Já para a antropóloga Mary Douglas, a aceitabilidade do risco, provém de que ao conviver com os riscos, os indivíduos expostos a eles, não os identificam como tais, pois já se acostumaram acreditando ser algo comum, ou seja, é algo que faz parte de suas vidas, não os percebendo.

Questionados sobre os problemas de saúde pela exposição ao uso de agrotóxicos na lavoura, $7,9 \%$ dos entrevistados relataram apresentar problemas de saúde relacionada ao uso de venenos e agrotóxicos na lavoura. Essa porcentagem baixa pode ser relacionada com a questão anterior, já que na sua maioria, seu trabalho não necessitava do uso destes produtos, logo não ficariam expostos aos riscos, e por isso não apresentariam problemas de saúde em relação ao uso. Porém, praticamente, a metade daqueles que relataram a necessidade do uso de venenos/agrotóxicos no seu trabalho (16,9\%), apresentou algum problema de saúde, revelando que os danos de seu uso causa a saúde do sujeito. Baseado na evidencia de que o uso de agrotóxicos é prejudicial à saúde de qualquer ser vivo (de forma momentânea ou posterior) e mesclando a análise do discurso dos entrevistados, muitos destes não relacionam seus problemas de saúde atuais, devido a sua exposição anterior ao agrotóxico, todavia desconsideram que este uso possa também ter contribuído para que a maioria relatasse não apresentar problema de saúde decorrente ao seu uso de defensivos.

\section{CONCLUSÕES}

De forma geral constatamos que existe a percepção de risco pela maioria dos entrevistados, estando cientes dos danos que o uso de agrotóxico causa a saúde e ao meio ambiente. Verifica-se também que estes acreditam na possibilidade do cultivo sem o uso de produtos químicos, como o realizado em plantações pequenas, destinadas para o consumo próprio sem visar lucro. Entretanto, para quase $8 \%$ dos entrevistados afirmam que usam defensivos em sua prática. Este uso pode ser justificado pela dificuldade de desenvolvimento das plantas, mas também vinculado ao aumento de produção e de rentabilidade, ou ainda pela demanda de seu trabalho. Arguimos que, ao utilizar agrotóxico devido ao seu trabalho, mesmo sabendo do risco envolvido, o individuo sujeita-se a este por depender desta prática para o seu sustento, assumindo, uma atitude passiva frente a ele, conforme proposto por Anthony Giddens. Sendo assim, a pessoa estará aceitando o risco, ou seja, pelo tempo e pela rotina, o processo torna-se natural e uso de agrotóxicos já faz parte de uma cultura e, portanto gera a aceitabilidade do mesmo, entrando assim, em concordância com os estudos da "aceitabilidade do risco" de Mary Douglas.

Questiona-se o crescente uso dos agrotóxicos, pois esta prática assume um papel preocupante, em decorrência dos prejuízos que causam ao meio ambiente, contaminando o solo, ar, água, alimentos. Essa contaminação por parte desses produtos químicos são riscos que ultrapassam os limites aceitáveis à vida, devido a seus resíduos em todas as frentes, inclusive nos alimentos. Os alimentos são necessários à sobrevivência humana, independente do lugar, hora e local a pessoa de qualquer classe social estará exposta ao risco (Beck, 1992) da oferta de um alimento contaminado pelo uso de agrotóxico.

Por fim, acredita-se que este estudo tenha de ter uma abrangência maior, buscando uma análise interdisciplinar com outras áreas das ciências ambientais, para além da sociologia, como: Biologia, Química, Ciências dos Alimentos, Agronomia, Medicina, Psicologia entre outras.

\section{REFERÊNCIAS}

BAUMAN, Z. Globalização: as consequências humanas. Rio de Janeiro: Jorge Zahar, 1998. 
BECK, Ülrich. Risk society. Towards a new modernity. Londres: Sage Publications, 1992.

BECK, Ülrich. The brave new World of work. Oxford: Polity Press, 2000.

BECK, Ülrich. La Sociedad del Riesgo Global. Madrid: Siglo Veintiuno, 2002.

DOUGLAS, Mary. La aceptabilidad del riesgo según las ciencias sociales. Barcelona: Paidós, 1996.

FEPAM. Qualidade das águas da Bacia Hidrográfica do Rio dos Sinos. Disponível em: < http://www.fepam. rs.gov.br/qualidade/qualidade_sinos/sinos.asp>. Acesso em: 10 jan. 2012.

G1. No RS, prefeitos querem proibir uso de água dos rios no cultivo do arroz. Disponível em: <http:// g1.globo.com/economia/agronegocios/noticia/2011/12/municipios-gauchos-querem-proibir-uso-de-agua-dos-rios-no-cultivo-do-arroz.html)>. Acesso em: 10 jan. 2012.

GIDDENS, A [et al.]; BERIAIN, Josetxo. Las consecuencias perversas de la modernidad: modernidad, contingencia y riesgo. Barcelona: Anthropos, 1996, 283p.

GOFFMAN, Erving. Framy Analysis, Los Marcos de la experencia. Madrid: CIS, 2006.

GRISOLIA, Cesar Koppe. Agrotóxicos. Mutações, câncer e reprodução. Brasília: Editora Universidade de Brasília, 2005, 392p.

GUIVANT, Júlia S. Reflexividade na Sociedade de Risco: conflitos entre leigos e peritos sobre os agrotóxicos, p. 281-303. In: Herculano, Selene (org), Qualidade de vida e riscos ambientais. Niterói: Editora da UFF, 2000.

GUIVANT, Júlia S. Riscos alimentares: novos desafios para a sociologia ambiental e a teoria social, p.89-99. In: Desenvolvimento e meio ambiente. Paraná: Editora da UFPR, 2002.

HUNSCHE, Carlos. O biênio 1824/25 da imigração e colonização alemã no Rio Grande do Sul. Porto Alegre: A Nação, 1975.

IBGE: Instituto Brasileiro de Geografia e Estatítica. Censo agropecuário de 2006. Disponível em: <http:// www.ibge.gov.br/home/estatistica/economia/agropecuaria/censoagro/2006/agropecuario.pdf>. Acesso em: 29 dez. 2011.

IBGE: Instituto Brasileiro de Geografia e Estatítica. Nota técnica do Censo Agropecuário de 2006. Disponível em: <http://www.ibge.gov.br/home/estatistica/economia/agropecuaria/censoagro/brasil_2006/notatecnica. pdf $>$. Acesso em: 29 dez. 2011.

LENMANN, Dieter. Bodas de Couro. Porto Alegre: Metrópole, 2000.

PERES, Frederico. É veneno ou é remédio? Os desafios da comunicação rural sobre os agrotóxicos. Rio de Janeiro: Escola Nacional de Saúde Pública, Fundação Oswaldo Cruz, 1999.

PERES, Frederico e MOREIRA, Josino Costa. É veneno ou remédio? Rio de Janeiro: FIOCRUZ, 2003, 384 p.

VETAGRO. Decretado o fim da produção de arroz no Vale do Rio dos Sinos. Disponível em: <http://www. vetagro.com.br/informativo_le.php?idinfo=735\&nomeinfo=info735\&pagatual=0>.Acesso em: 10 jan. 2012 . 